\title{
Performance Analysis of Wireless Communication Systems' Traffic using Erlang Models: A Case Study of Yankari Game Reserve in
}

\section{Nigeria}

\author{
M. A. Gadam, A.M Maryam,E. Kevin, A.Y Ibrahim \\ Federal Polytechnic Bauchi, Nigeria \\ magadam@ieee.org \\ Abubakar Tafawa Balewa University Bauchi, Nigeria \\ Maryam_naya84@yahoo.com \\ Federal Polytechnic Bauchi, Nigeria \\ keeteng@fptb.edu.ng \\ Federal Polytechnic Bauchi, Nigeria \\ aiibrahim@fptb.edu.ng
}

\begin{abstract}
In any developing nation such as Nigeria, the level of her telecommunication and ICT development is an issue that requires adequate planning especially when consideration is given to the amount of traffic and the available bandwidth in the system. Tourism is one of the areas that the Nigerian Government is considering as a source of internally generated revenue and therefore, infrastructure such as traffic free wireless communication system and fast internet accesss need to be provided to woo tourists and make them feel at home. This cannot be achieved unless the traffic is modeled and its analyzed .Yankari Game Reserve is one of the tourist attraction located in Bauchi state, north-eastern Nigeria. Wireless Communication and internet traffic is analysed in this paper using erlang models to improve the systems' quality of service. It is shown that a multi-server system is the most appropriate model to reduce amount of delay in a peak period. It is also proven that delay time is reduced significantly when the number of users increases in a multi-server system.
\end{abstract}

\section{Keywords}

Multi-server system, erlang models ,Yankari Game reserve, queuing models, delay models

\section{Academic Discipline And Sub-Disciplines}

Computer science, Information Technology, Tourism development

\section{SUBJECT CLASSIFICATION}

Information and Communication Technology

\section{TYPE (METHOD/APPROACH)}

Analysis and Modelling

\section{Council for Innovative Research}

Peer Review Research Publishing System

\section{Journal: INTERNATIONAL JOURNAL OF COMPUTERS \& TECHNOLOGY}

Vol 13, No 11

www.ijctonline.com, editorijctonline@gmail.com 


\section{INTRODUCTION}

Wireless communication and multimedia services are part of the tourism infrastructure that attracts and make the Game reserve easily accessible to visitors. A well modelled wireless communication and multimedia system makes it easier for visitors from various part of the world to communicate with their family and love ones while away from home. In view of this, a well modelled wireless system for Yankari Game Reserve is considered among the most important infrastructures that attract visitors to the park and analysis of traffic model is the main focus of this work.

Yankari Game Reserve is a wildlife park located in the south-east part of Bauchi state, Nigeria. It covers an area of about $2,244 \mathrm{~km}^{2}\left(870 \mathrm{~m}^{2}\right)$ of uninhabited savannah woodland, at an elevation of approximately 2429-4164 meters, and is home to several natural warm water springs, as well as a wide variety of flora and fauna. The location of Yankari National Park in the heartland of the West African savannah makes it a unique and perfect place for travelers who love wild life viewing, jungle trekking, hiking, rock climbing, camping and many more. It is well established as one of the most popular ecotourism in Nigeria [1, 2]. The Reserve's main entrance is at Mainamaji village, about $29 \mathrm{~km}$ from Dindima. It is located within the Duguri, Pali and Gwana districts of Alkaleri Local Government Area of Bauchi State. This LGA has a population 208,202 people occupying a total land area of $7,457.78 \mathrm{~km}^{2}[2,3]$.

In 2000, Yankari Game Reserve hosted over 20,000 tourists from over 100 countries and with a projection of over 100,000 tourists by the year 2020. This places it among the most popular tourist destinations in Nigeria and, if the tourism infrastructure most is properly analysed and appropriate recommendations for their sustainable development made, it could become a significant part in the development and promotion of tourism throughout Nigeria. It is one of a few remaining areas left in West Africa where wild animals are protected in their natural habitat [4].

The main focus of this paper is on how to model wireless communication system traffic at Yankari Game Reserve to improve quality of service (delay and call blocking). The probability of delay and call blocking are the performance index to be used to measure the quality of service of the system model. This paper will achieve the following objectives:

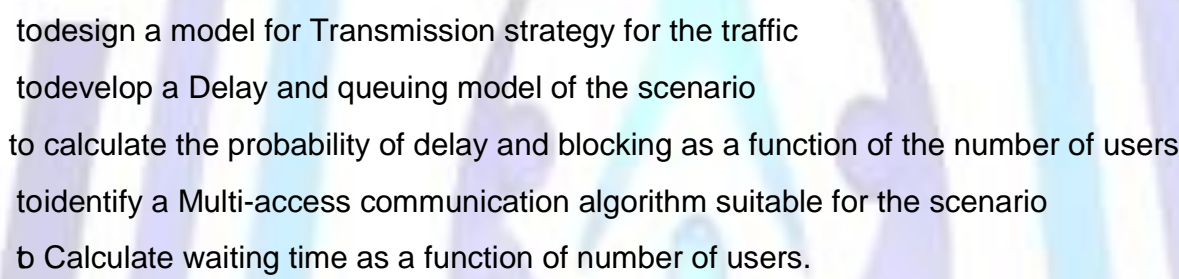

\section{Overview IEEE 802.11n Wireless LAN Technology}

The IEEE802.11n wireless LAN technology is adopted for the purpose of modeling the communication system in this project [5]. This is because of technology incorporated in this among which are MIMO (Multiple in Multiple Out) which utilizes multiple antennas to transfer several stream of data at the same time. Channel bounding technology and Payload optimization which can use two separate non-overlapping channels at the same time to transmit data and allow more data to be loaded in a packet respectively are some of the benefits of this technology used. This also manifest in their high reliability, optimal throughput, predictable coverage and ease of migration to older technology. As a result, we forecast all these will be useful in the online booking, mailing and voice over IP being used by the visitors.

The radio access technology adopted for deployment in Yankari Game Reserve is the wireless LAN (IEEE 802.11n) technology because of its reliability, predictable coverage, raw speed, and throughput [6]. Greater client densities can be supported because of high signal to noise ratio (SNR) which translates to more reliable communication. The $802.11 \mathrm{n}$ operates in both the 2.4-GHz (802.11b and $\mathrm{g})$ and 5-GHz (802.11a) radio bands as depicted in fig.1. The improvement in the MAC layer results in a greater improvement in the throughput of the wireless technology [5].

The retransmission strategy in $802.11 \mathrm{n}$ is an improved forward error correction (FEC). This is a system of error control whereby the sender adds redundant data to allow the receiver to detect errors. FEC convolutional codes are block codes and therefore suitable for data link layer because they process a continuous bit stream [7]. The MAC protocol data unit (MPDU) is received either correctly or incorrectly and is determined by the cyclic redundancy check (CRC) of that MPDU. Failure to receive the MPDU leads to retransmission. The FEC codes are also known as block erasure codes.

Queuing is an important and basic framework to analyze delay in a network. Delays are predicted in a systems based on assumptions. Sometimes it is difficult to get an accurate delay prediction but some models are used for approximate delays predictions. A delay consists of four components namely; the process delay, the queuing delay, the transmission delay, and propagation delay. The priority queuing model gives priority to some packets based our design the preemptive priority is adopted. The voice packets are given high priority and therefore whenever there is voice packet on the system, the server will suspend what it is doing and attend the voice packets. The $\mathrm{M} / \mathrm{M} / \mathrm{m} / \mathrm{m}$ delay model is adopted for this system. The principal quantity of interest in this model is the blocking probability.

The wireless technology adopted for this is WLAN and it employed an access method known as Carrier Sense Multiple Access with Collision Avoidance (CSMA/CA) to avoid collision. CSMA/CA creates a reservation on the channel for use by a specific conversation. While a reservation is in place, no other device may transmit on the channel thus possible collisions are avoided. Nodes wait for a short delay to listen and know whether other nodes are transmitting or not, if 
nodes detects idle periods it quickly initiate transmission after the detection. This type of strategy, is called carrier sense multiple access.

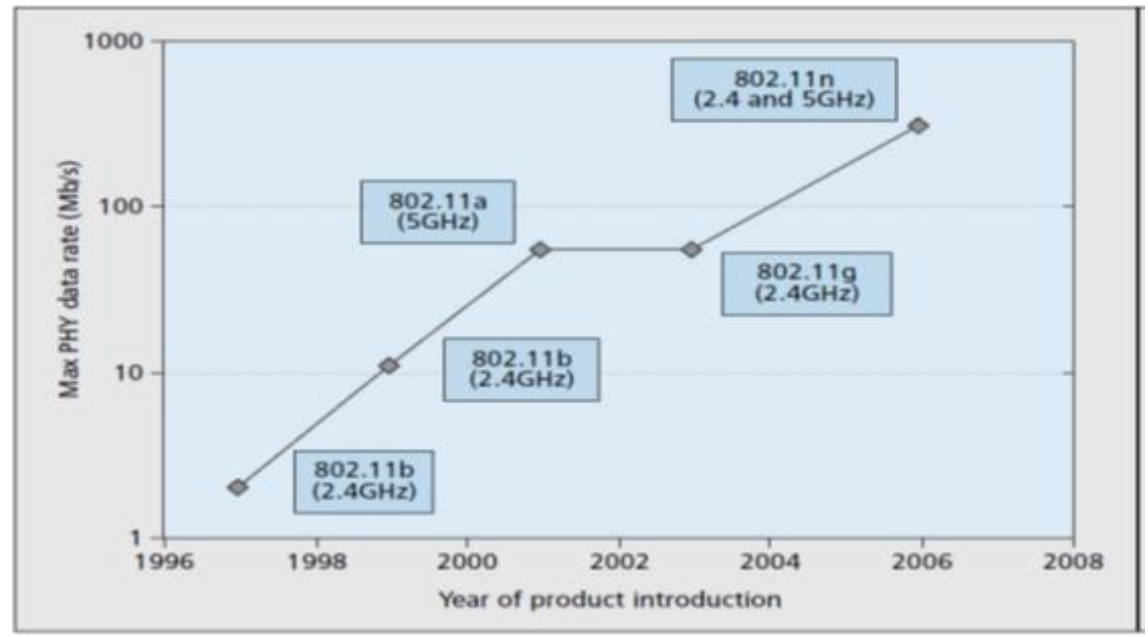

Fig 1: IEEE 802.11 WLAN evolution

\section{TRAFFIC ANALYSIS AND SYSTEM MODELLING}

The estimated potential wireless users who connected to the network in the area are categories into different percentages to suit the population of the area which are: $10 \%, 20 \% \ldots .100 \%$. This is because the people are not living there permanent; they are coming and leaving depending on the seasons. We suggest that the traffic types which are suitable in the area are voice and data. This is because we believe that voice and data are the main communication means which is going to be used by the visitors who are going to Taman Negara part.

Moreover, since we suggested that the type of wireless network which is suitable at the area is IEEE 802.11n WLAN, it utilizes multiple wireless antennas in tandem to transmit and receive data. The associated term MIMO (Multiple Input, Multiple Output) refers to the ability of $802.11 \mathrm{n}$ and similar technologies to coordinate multiple simultaneous radio signals. MIMO increases both the range and throughput of a wireless network [9].

An additional technique employed by $802.11 \mathrm{n}$ involves increasing the channel bandwidth. As in $802.11 \mathrm{a} / \mathrm{b} / \mathrm{g}$ networking, each $.11 \mathrm{n}$ device uses a preset Wi-Fi channel on which to transmit. Each .11n channel will use a larger frequency range than these earlier standards, also increasing data throughput .IEEE.802.11n connections support maximum theoretical network bandwidth up to 300 Mbps depending primarily on the number of wireless radios incorporated into devices. The figure 2 below shows data/voice system model for Yankari National Park.

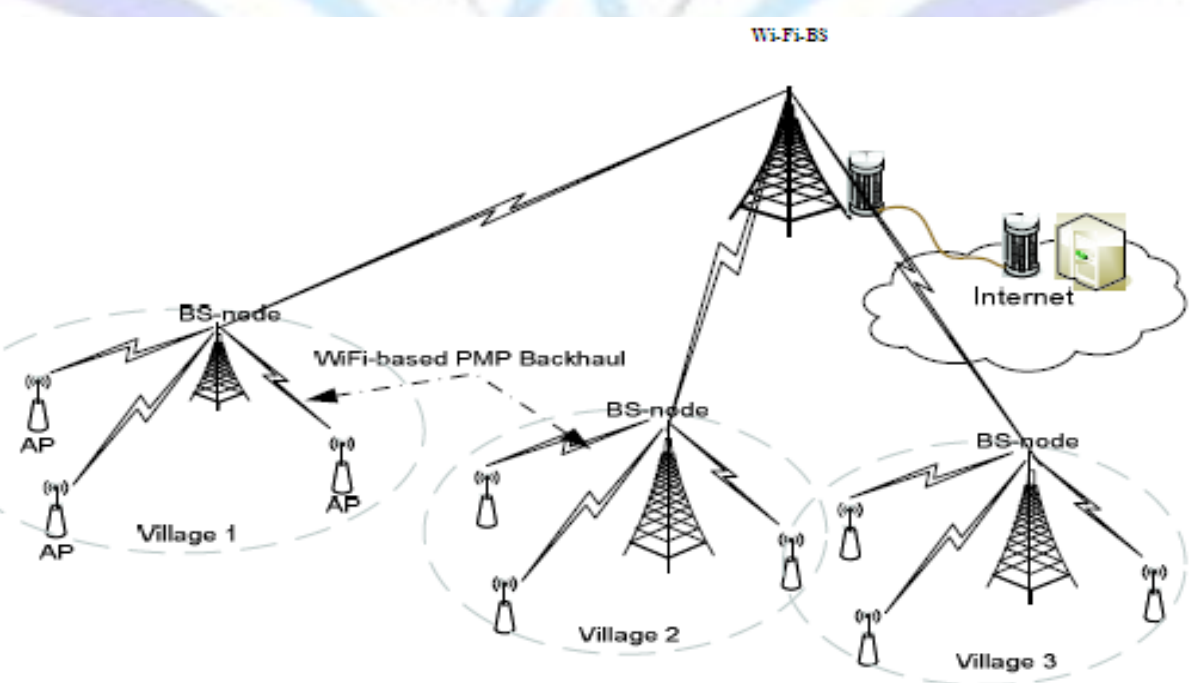

Fig2:Yankari Game Reserve Traffic Model 


\section{Retransmission strategy}

Retransmission strategy in these two traffic types which integrated into a common channel will be Selective Repeat automatic repeat request ( $A R Q$ ) for data packets while Forward Error Correction (FEC) will be used for voice [10]. This will allow us to use the same code for data and voice assuming that the decoder will switch to error detection mode when it receives a data packet and to error correction mode when it receives a voice packet. Data Transmission from source to destination in case of voice, there would be no retransmissions. Voice and data messages will be treated as two different classes of customers sharing a common queue with voice having priority (preemptive).

\section{Delay and queuing model suitable for the scenario}

Delay and queuing model suitable for the scenario is multi-severs system (i.e. $M / M / m / m$ )[11]. This is because this type of queue will not put customers in a queue and wait for long time while waiting for the service. So when all servers are busy serving other customers the incoming calls will be dropped or blocked to avoid wasting of customer's time and improving performance. $\mathrm{M} / \mathrm{M} / \mathrm{m} / \infty$ type model is not suitable because will allow calls to be placed in a queue and waiting long time for the service and as a result wasting customer's time [12],[13].Please use a 9-point Arial font, or other Roman font with serifs, as close as possible in appearance to Arial in which these guidelines have been set. The goal is to have a 9-point text, as you see here. Please use sans-serif or non-proportional fonts only for special purposes, such as distinguishing source code text. If Arial is not available, try the font named Computer Modern Roman. On a Macintosh, use the font named Times. Right margins should be justified, not ragged.

\section{Multi-access communication algorithm suitable for the scenario}

Multi-access communication algorithm suitable for the scenario is Carrier senses multiple accesses with collision avoidance (CSMA/CA). Within a WLAN, the lack of well-defined boundaries makes it impossible to detect if collisions occur during transmission. Therefore, it is necessary to use an access method on a wireless network that ensures collisions do not occur. Wireless technology uses an access method called Carrier Sense Multiple Access with Collision Avoidance (CSMA/CA) [5]. CSMA/CA creates a reservation on the channel for use by a specific conversation. While a reservation is in place, no other device may transmit on the channel thus possible collisions are avoided.

How does this reservation process work? If a device requires use of a specific communication channel in a BSS, it must ask permission from the AP. This is known as a Request to Send (RTS). If the channel is available, the AP will respond to the device with a Clear to Send (CTS) message indicating that the device may transmit on the channel. A CTS is broadcast to all devices within the BSS. Therefore, all devices in the BSS know that the requested channel is now in use. Once the conversation is complete, the device that requested the channel sends another message to the AP known as an Acknowledgement (ACK). The ACK indicates to the AP that the channel can be released. This message is also broadcast to all devices on the WLAN. All devices within the BSS receive the ACK and know that the channel is once again available.

\section{TRAFFIC CALCULATIONS, RESULTS AND DISCUSSIONS}

This section illustrates the computation of probability of delay and probability of blocking users in the modeled wireless communication system. Assuming that no. of potential users are $10 \%, 20 \%, 30 \%, 40 \%, 50 \%, 60 \%, 70 \%, 80 \%, 90 \%$, and $100 \%$ as shown in table 1 below. The percentage that illustrated above is represented potential wireless users who can be connected to the network.

\section{Probability of delay}

Erlang $\mathrm{C}$ excel function to calculate probability of delay is = ErlcFractionDelayed(5, L). Where 5 is the number of servers and $L$ is the traffic intensity (load). In the table 1, the function (Erlang $C$ function) from excel 2007 was used to calculate the probability of delay. Then we used traffic intensity $(L)$ with 5 servers (channels) where $L$ is equal to lambda * $d$. Lambda is average call arrival rate (call/min) $d$ is average call duration (min/call) to calculate the traffic intensity. The distribution and calculations are show in table 1. Number of calls per hour is the busy hour (i.e. many customers call their friends/relatives back home).

The following parameters were set based on the expected traffic there in the area;

Total number of users $=81,989$

Average call duration $=5 \mathrm{~min}$

Number of servers $=5$

Load $=$ No. of calls/hour ${ }^{*}$ average call duration 
Table 1:Probability of delay for $\mathrm{M} / \mathrm{M} / \mathrm{m} / \infty$ using Erlang $\mathrm{C}$

\begin{tabular}{|c|c|c|c|c|c|c|}
\hline S/no. & No. of users & $\begin{array}{l}\text { No. of users } \\
\text { (\%) }\end{array}$ & $\begin{array}{l}\text { No. of } \\
\text { call/hr }\end{array}$ & $\begin{array}{l}\text { Intensity } \\
(\text { Load)/min }\end{array}$ & $\begin{array}{c}\text { Probability } \\
\text { of Delay }\end{array}$ & $\begin{array}{l}\text { Probability } \\
\text { of Delay } \\
\text { (\%) }\end{array}$ \\
\hline 1.0 & 8198.9 & 10.0 & 80 & 1.33 & 0.0126 & 1.2612 \\
\hline 2.0 & 16397.8 & 20.0 & 120 & 2.00 & 0.0597 & 5.9701 \\
\hline 3.0 & 24596.7 & 30.0 & 180 & 3.00 & 0.2362 & 23.6152 \\
\hline 4.0 & 32795.6 & 40.0 & 240 & 4.00 & 0.5541 & 55.4113 \\
\hline 5.0 & 40994.5 & 50.0 & 280 & 4.67 & 0.8386 & 83.8578 \\
\hline 6.0 & 49193.4 & 60.0 & 310 & 5.17 & 1.0000 & 100.000 \\
\hline 7.0 & 57392.3 & 70.0 & 370 & 6.17 & 1.0000 & 100.000 \\
\hline 8.0 & 65591.2 & 80.0 & 410 & 6.83 & 1.0000 & 100.000 \\
\hline 9.0 & 73790.1 & 90.0 & 480 & 8.00 & 1.0000 & 100.000 \\
\hline 10.0 & 81989.0 & 100.0 & 530 & 8.83 & 1.0000 & 100.000 \\
\hline
\end{tabular}

Figure 3 depicts the graph of probability of delay versus number of users, the figure shows that when the number us users increases the probability of delay also increases but it remain steady (constant) when the probability of delay reaches infinity (i.e. probability of delay became 1 ).

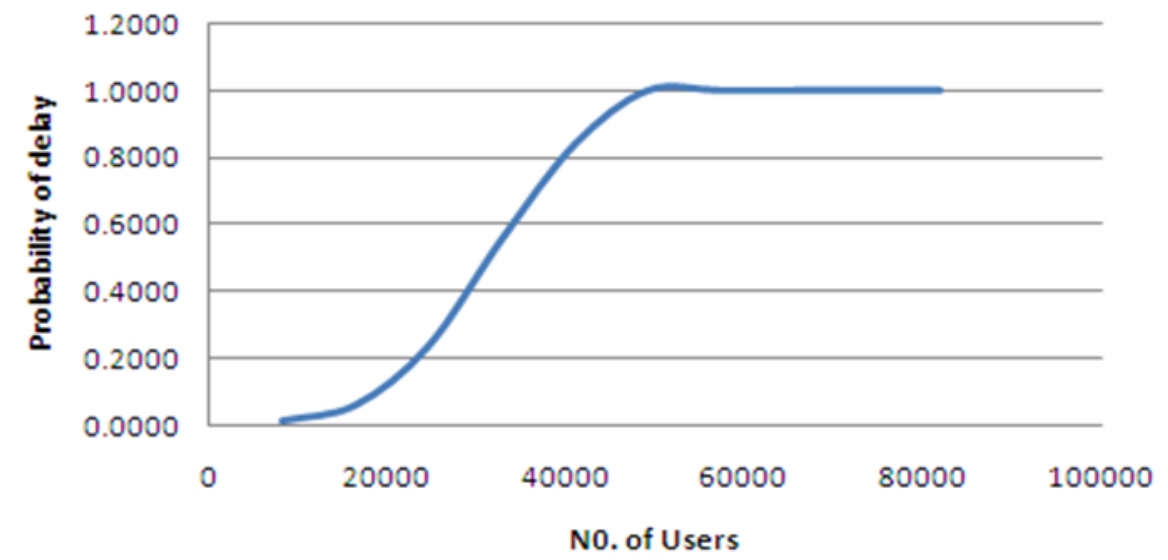

Fig3: Graph of probability of delay vs no.of users

\section{Probability of call blocking}

Erlang $\mathrm{C}$ Excel function to calculate probability of blocking is = ErlBBlockage $(5, \mathrm{~L})$. Where 5 is the number of servers and $L$ is the traffic intensity (load).

In Table 2, the function (Erlang B function) was used from excel 2007 to calculate the probability of blocking as shown. Then traffic intensity $(L)$ with 5 servers (channels) was used, where $L$ is lambda * $d$. lambda is average call arrival rate (call/min) $d$ is average call duration ( $\mathrm{min} / \mathrm{call}$ ) to calculate the traffic intensity. The distribution and calculations are also shown on Table2. Number of calls per hour is the busy hour (i.e. many customers call their friends/relatives back home).

Total number of users $=81,989$

Average call duration $=5 \mathrm{~min}$

Number of servers $=5$

Load $=$ No. of calls/hour ${ }^{*}$ average call duration 
Table 2: Probability of call blocking for $M / M / m / m$ queue using Erlang $B$

\begin{tabular}{|c|c|c|c|c|c|c|}
\hline S/no. & No. of users & $\begin{array}{l}\text { No. of users } \\
\text { (\%) }\end{array}$ & $\begin{array}{l}\text { No. of } \\
\text { call } / \mathrm{hr}\end{array}$ & $\begin{array}{c}\text { Intensity } \\
(\text { Load)/min }\end{array}$ & $\begin{array}{l}\text { Probability } \\
\text { of blocking }\end{array}$ & $\begin{array}{l}\text { Probability of } \\
\text { blocking (\%) }\end{array}$ \\
\hline 1.0 & 8198.9 & 10.0 & 80 & 1.33 & 0.0093 & 0.9280 \\
\hline 2.0 & 16397.8 & 20.0 & 120 & 2.00 & 0.0367 & 3.6697 \\
\hline 3.0 & 24596.7 & 30.0 & 180 & 3.00 & 0.1101 & 11.0054 \\
\hline 4.0 & 32795.6 & 40.0 & 240 & 4.00 & 0.1991 & 19.9067 \\
\hline 5.0 & 40994.5 & 50.0 & 280 & 4.67 & 0.2572 & 25.7240 \\
\hline 6.0 & 49193.4 & 60.0 & 310 & 5.17 & 0.2982 & 29.8242 \\
\hline 7.0 & 57392.3 & 70.0 & 370 & 6.17 & 0.3719 & 37.1880 \\
\hline 8.0 & 65591.2 & 80.0 & 410 & 6.83 & 0.4147 & 41.4739 \\
\hline 9.0 & 73790.1 & 90.0 & 480 & 8.00 & 0.4790 & 47.9008 \\
\hline 10.0 & 81989.0 & 100.0 & 530 & 8.83 & 0.5178 & 51.773 \\
\hline
\end{tabular}

Figure 4 shows the graph of blocking probability versus number of users. The figure shows that when the number of users increases the probability of blocking also increases (i.e. blocking probability is in direct proportion to the number of users).

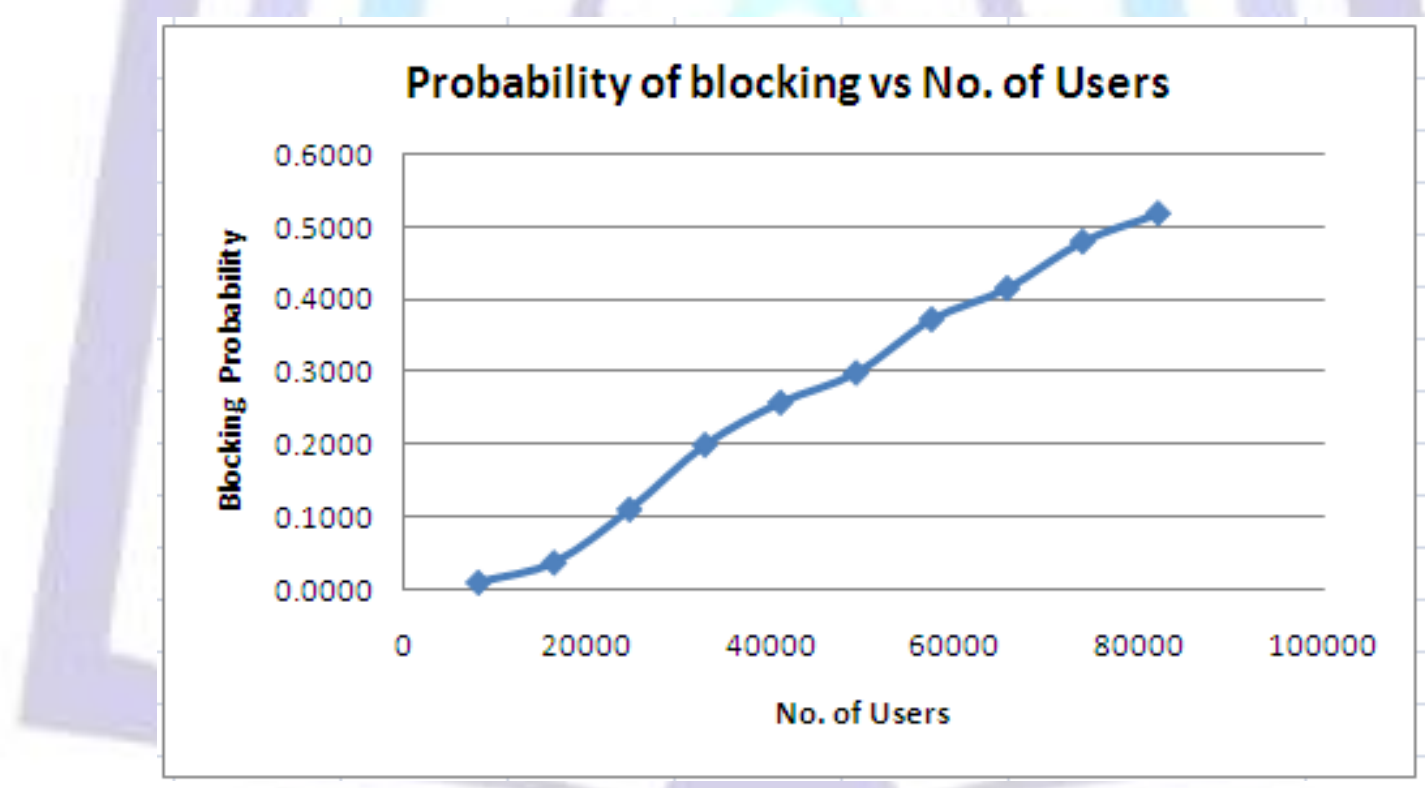

Fig4: Graph of probability of blocking versus No. of users

\section{Waiting time}

Excel function for calculating waiting time is = erlcwait(5, L,300). Where 5 is the number of servers and $L$ is the traffic intensity (load), and 300 is the call duration in second (5 $\times 60$ seconds).

Waiting time as a function of number of users using excel function;

Erlcwait(nsrv, trafficlnErlangs, aht Seconds), where aht is average handle time 5 minutes (300 sec) nsrv - number of servers $=5$. 
Table 2: Call waiting time

\begin{tabular}{|c|c|c|c|c|c|}
\hline S/no. & No. of users & $\begin{array}{l}\text { No. of users } \\
\text { (\%) }\end{array}$ & $\begin{array}{c}\text { No. of } \\
\text { call/hr }\end{array}$ & $\begin{array}{c}\text { Intensity } \\
\text { (Load)/min }\end{array}$ & $\begin{array}{c}\text { Call waiting time } \\
\text { (secs) }\end{array}$ \\
\hline 1.0 & 8198.9 & 10.0 & 80 & 1.33 & 0.0001 \\
\hline 2.0 & 16397.8 & 20.0 & 120 & 2.00 & 0.0018 \\
\hline 3.0 & 24596.7 & 30.0 & 180 & 3.00 & 0.0496 \\
\hline 4.0 & 32795.6 & 40.0 & 240 & 4.00 & 0.4407 \\
\hline 5.0 & 40994.5 & 50.0 & 280 & 4.67 & 1.3355 \\
\hline 6.0 & 49193.4 & 60.0 & 310 & 5.17 & 2.7202 \\
\hline 7.0 & 57392.3 & 70.0 & 370 & 6.17 & 9.1670 \\
\hline 8.0 & 65591.2 & 80.0 & 410 & 6.83 & 18.6858 \\
\hline 9.0 & 73790.1 & 90.0 & 480 & 8.00 & 61.3770 \\
\hline 10.0 & 81989.0 & 100.0 & 530 & 8.83 & 159.5386 \\
\hline
\end{tabular}

In table 3,Erlang $C$ function was used to calculate the waiting time in the queue as shown in that table 3.Traffic intensity (L) with 5 servers (channels) was used, where $L=$ lambda * $d$. Lambda is average call arrival rate (call/min) $d$ is average call duration ( $\mathrm{min} / \mathrm{call}$ ) to calculate the traffic intensity. The distribution after computations are shown on Table 3 . Number of calls per hour is the busy hour (i.e. many customers call their friends/relatives back home).

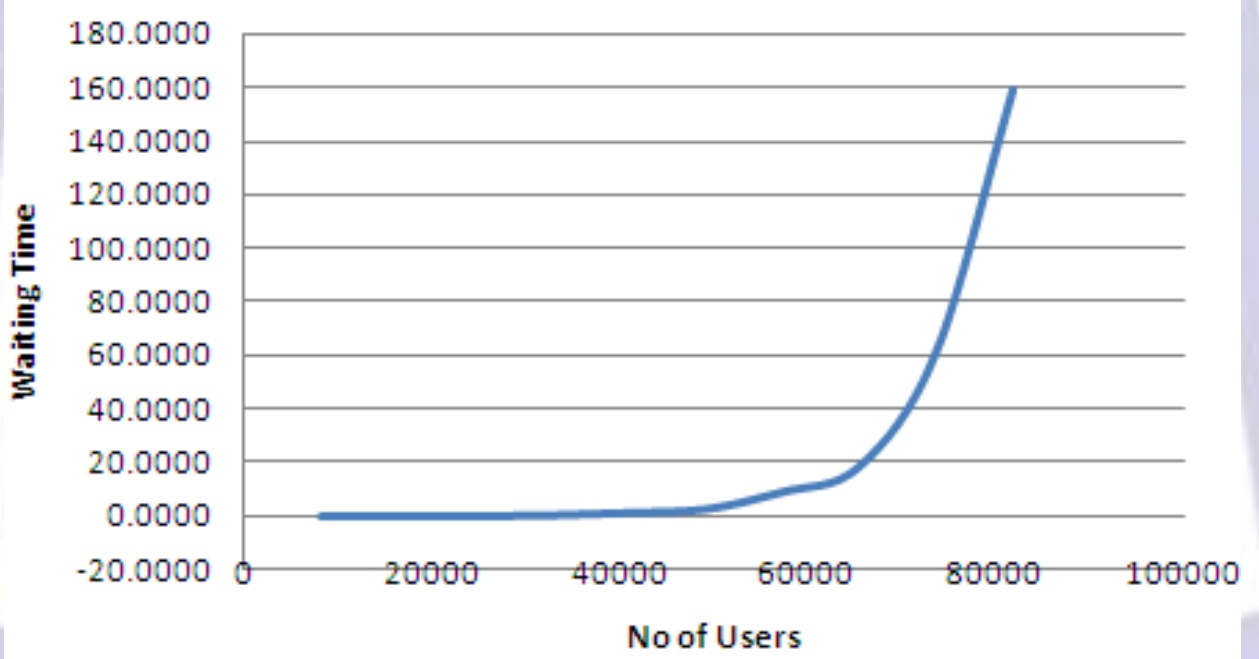

Fig.5: Graph of call waiting time vs time

The figure 5 above shows the graph of waiting time versus number of users, as we can see on the figure that when the number of users increases the call waiting time also increases.

\section{CONCLUSION}

Erlang models were employed to accurately capture and analyse the communication traffic in Yankari Game Reserve. From our modelling traffic calculations, it shows that when the traffic intensity (number of users) increased the probability of blocking and delaying are increased, but they are reduced when the numbers of servers were increased. And the waiting time for delaying queuing model increased when the number of users increased but reduced when the number of users decreases.

Moreover, according to the traffic calculation, it can be deduced that the queuing model suitable for the scenario is Multiservers without delay (i.e. $\mathrm{M} / \mathrm{M} / \mathrm{m} / \mathrm{m}$ ) so that customers can retry to call later when the servers are not busy. This model when implemented at Yankari Game reserve will improve the quality of communication and thereby makes visitors feel at home whenever they intend to communicate with their loved ones. 


\section{REFERENCES}

[1] I. Mohammed, A. I. Shehu, M. B. Adamu, and U. F. Saleh, "Comparative analysis of fauna numerical characteristic of Yankari Game Reserve from 1980-2008," Environ. Res. J., vol. 4, no. 2, pp. 177-181, 2010.

[2] M. Danlami, "ANALYSIS OF THE ENVIRONMENTAL SUSTAINABILITY OF TOURISM INFRASTRUCTURE DEVELOPMENT AT YANKARI GAME RESERVE."

[3] A. O. Nnaji, "e-Review of Tourism Research (eRTR), Vol. 9, No. 6, 2011 http://ertr.tamu.edu,"

vol. 9, no. 6, pp. 265-278, 2011.

[4 ] C. I. C. Okoli and U. Chigozie, "ATTITUDE TO RECREATION $\square$ : A HINDERANCE TO DEVELOPMENT OF TOURISM INDUSTRY IN NIGERIA,” vol. 2, no. 2, pp. 59-68, 2013.

[5] R. Leutert and L. Netservices, "Inside 802.11n," no. 2, March, 2009.

[6] E. Sunday, "802 . 11n $\square$ : The Next Generation of Wireless Performance," no. June 2007, pp. 1-25, 2011.

[7] J. Li, "Evaluating Forward-Error Correction and 802.11 Mesh networks," in 2012 7TH INTERNATIONAL CONFERENCE ON SYSTEM OF SYSTEMS ENGINEERING SOSE, 2012, pp. 137-139.

[8] Marcini, M. , "Cruising: A guide to the cruise industry, "2nd, Edition. Pp1-100. 7. (2004).

[9] I. Pefkianakis, Y. Hu, S. H. Y. Wong, H. Yang, and S. Lu, "MIMO rate adaptation in 802.11 n wireless networks," Proc. ... Proc., pp. 257-268, 2010.

[10] M. Zorzi, Performance of FEC and ARQ error control in bursty channels under delay constraints, vol. 2, no. 1. 1998.

[11] H. M. S. H. M. Soo and J.-M. C. J.-M. Chung, Analysis of nonpreemptive priority queueing of MPLS networks with bulk arrivals, vol. 3, no. 6. 2002, pp. 409-414.

[12] D. M. B. Masi, M. J. Fischer, and D. A. Garbin, Modeling the performance of low latency queueing for emergency telecommunications. leee, 2007, pp. 2266-2275.

[13] Y. G. Kim and P. S. Min, On the prediction of average queueing delay with self-similar traffic, vol. 5. 2003. 